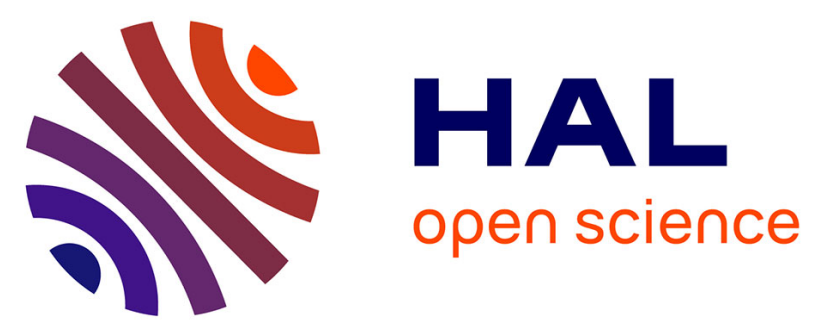

\title{
Production and validation of CR-39-based dishes for alpha-particle radiobiological experiments
}

Sylvain Gaillard, Vincent Armbruster, Mark A Hill, Tijani Gharbi, Michel Fromm

\section{- To cite this version:}

Sylvain Gaillard, Vincent Armbruster, Mark A Hill, Tijani Gharbi, Michel Fromm. Production and validation of CR-39-based dishes for alpha-particle radiobiological experiments. Radiation Research, 2005, 163 (3), pp.343-350. 10.1667/rr3307 . hal-00516007

\section{HAL Id: hal-00516007 https://hal.science/hal-00516007}

Submitted on 7 Oct 2021

HAL is a multi-disciplinary open access archive for the deposit and dissemination of scientific research documents, whether they are published or not. The documents may come from teaching and research institutions in France or abroad, or from public or private research centers.
L'archive ouverte pluridisciplinaire HAL, est destinée au dépôt et à la diffusion de documents scientifiques de niveau recherche, publiés ou non, émanant des établissements d'enseignement et de recherche français ou étrangers, des laboratoires publics ou privés.

\section{(c)(1)}

Distributed under a Creative Commons Attribution| 4.0 International License 


\title{
Production and Validation of CR-39-Based Dishes for $\alpha$-Particle Radiobiological Experiments
}

\author{
Sylvain Gaillard, ${ }^{a, 1}$ Vincent Armbruster, ${ }^{b}$ Mark A. Hill, ${ }^{c}$ Tijani Gharbi ${ }^{b}$ and Michel Fromm ${ }^{a}$ \\ ${ }^{a}$ Laboratoire de Microanalyses Nucléaires and ${ }^{b}$ Laboratoire d'Optique P.M. Duffieux, UFR Sciences et Techniques, Université de Franche-Comté, \\ 25030 Besançon Cedex, France; and ${ }^{c}$ Radiation and Genome Stability Unit, Medical Research Council, Harwell, \\ Oxfordshire OX11 ORD, United Kingdom
}

Gaillard, S., Armbruster, V., Hill, M. A., Gharbi, T. and Fromm, M. Production and Validation of CR-39-Based Dishes for $\alpha$-Particle Radiobiological Experiments. Radiat. Res. 163, 343-350 (2005).

The study of radiobiological effects induced in vitro by low fluences of $\alpha$ particles would be significantly enhanced if the precise localization of each particle track in the cell monolayer was known. From this perspective, we developed a new method based on tailor-made UV-radiation-cured CR-39, the production of which is described. Its validation both as a petri dish and as solid-state nuclear track detectors is demonstrated. With respect to the demands on solid-state nuclear track detectors in such experiments, these biologically compatible detectors have a controlled micrometric thickness that allows them to be crossed by the $\alpha$ particles. In this study, we present a method for obtaining 10- $\mu$ m-thick CR-39, its chemical characterization, and its properties as a solid-state nuclear track detector under the environmental conditions of radiobiological experiments. The experimental studies performed with $\mathbf{3 . 5}$ $\mathrm{MeV} \alpha$ particles show that their transmitted energy is sufficient enough to cross the entire cellular volume. Under optimal conditions, etched tracks are clearly defined $2 \mathrm{~h}$ after etching. Moreover, the UV-radiation-cured CR-39 represents an essentially zero background that is due to the short time between the production and use of the polymer. Under a confocal microscope, this thin solid-state nuclear track detector allows the precise localization of the impact parameter at the subcellular level. $\odot 2005$ by Radiation Research Society

\section{INTRODUCTION}

The biological effects of $\alpha$ particles are of particular interest since they are the main source of environmental radiation exposure for the general population, contributing

\footnotetext{
${ }^{1}$ Address for correspondence: Laboratoire de Microanalyses Nucléaires-Alain Chambaudet, UMR CEA-E4, UFR Sciences et Techniques, Université de Franche-Comté, 16, route de Gray, 25030 Besançon CEDEX, France; e-mail: sylvain.gaillard@univ-fcomte.fr.
}

$\sim 50 \%$ of the average effective dose from natural sources of ionizing radiation (1). For typical human exposures of concern in radiation protection, cells will only be exposed to individual $\alpha$-particle tracks, with the majority of cells not being hit, over a period of months to years. At low exposure levels, the insult to the cell nucleus remains the same, but the number of traversed nuclei decreases proportionally. In traversed cells, the high-LET $\alpha$ particles can deposit a large amount of energy (e.g. up to $0.4 \mathrm{~Gy}$ for a $5.5 \mathrm{MeV} \alpha$ particle traversing a spherical cell with a diameter of $8 \mu \mathrm{m}$ ) along a narrow path, resulting in a very nonhomogeneous distribution of initial damage within the cell and clustering of DNA damage on the scale of DNA and chromatin fibers (2). The traversed cell will typically attempt to repair the resulting DNA damage, which may lead to a variety of cellular responses, such as cell inactivation, apoptosis, inter- and intracellular signaling, chromosomal rearrangements and mutations. However, it is not just the traversed cell that responds; a wide variety of biological responses have been observed in cells that have not themselves received any energy deposition from ionizing radiation. Observed responses include the formation of sister chromatid exchanges (3-5), micronucleus formation $(6,7)$, changes in protein expression $(8,9)$, mutation (10), oncogenic transformation (11), and chromosome instability $(12,13)$. These nonirradiated cells are responding to "signals" produced by irradiated cells, which are transmitted between cells either by direct cell-to-cell contact, through gap junctions, or indirectly through a secreted factor. The phenomenon has been referred to as the bystander effect; at present the mechanisms and the risk implications of this effect are unknown (14-17). Various approaches have been used to study the bystander effects of high-LET particles, including conventional irradiation with low doses $(4,9)$, experiments transfer cell culture medium (18), partial shielding/co-culture systems $(11,19,20)$, and microbeams (21-23).

It is now possible with charged-particle microbeams to 
target all or a given number of cells with a predetermined number of charged-particle traversals that are targeted within the cells with approximately micrometer accuracy. It is therefore possible to discriminate the subsequent response of both irradiated and unirradiated cells. However, there are currently very few fully operational microbeams worldwide. An alternative approach, although less flexible, is to irradiate with a broad field of $\alpha$ particles from an isotope $\alpha$-particle source (typically ${ }^{241} \mathrm{Am},{ }^{210} \mathrm{Po}$ or ${ }^{238} \mathrm{Pu}$ ) and determine the position of the $\alpha$-particle traversals postirradiation using polymeric solid-state nuclear track detectors such as CR-39 or LR115 (24-26). Solid-state nuclear track detectors can also give information on the radiation field uniformity, divergence and particle fluence. They have the advantage that they are inexpensive and do not require the use of a particle accelerator and enable the study of the natural random Poisson distribution of particle tracks down to low fluences (low dose).

For such experiments, the solid-state nuclear track detector must be thin enough to allow the $\alpha$ particles to cross the detector with sufficient residual energy to create tracks in the cells. Moreover, since the detector material being used is also used as a substrate for cell culture, it must be biologically compatible. In addition, to be observed under an optical microscope, the latent tracks created in the detector must be chemically etched. This step is generally performed with a hot concentrated basic solution $(\mathrm{NaOH}$, $\mathrm{KOH})(27)$.

LR115, a red cellulose nitrate that is produced commercially and has the advantage of having a thickness of 12 $\mu \mathrm{m}$, is used by many research teams $(24,26,28)$, mainly for the dosimetry of radon and radon daughters. Its composition has recently been modified to prevent its red dye from diffusing into the nutritive medium necessary for cell growth (28), which could potentially stress the cells. In this case, a thin Mylar foil (maximum thickness about $3 \mu \mathrm{m}$ ) could be arranged above the detector $(24,28)$ as long as there is no movement between the two layers. However, this colorless LR115 does not allow a systematic and exact measurement of the track diameter, which thus results in extremely irregular shapes with blurred contours.

CR-39 (poly-allyl diglycol carbonate) is another solidstate nuclear track detector that has good properties for registration of light ions (28), which can be studied under a confocal microscope. Moreover, in contrast to LR-115 (28), this polymer can easily be sterilized using ethanol, after which cells can easily grow on it (29). However, this detector is available commercially with a minimum thickness of about $500 \mu \mathrm{m}$, which is too thick for radioisotope-produced $\alpha$ particles to traverse, and it is therefore unsuitable for simple radiobiological experiments.

Solid-state nuclear track detectors can be useful tools in radiobiological studies, including studies of the biological response within an irradiated cell and the co-localization of repair-related proteins to the site of traversal of the particle track. Furthermore, solid-state nuclear track detectors can
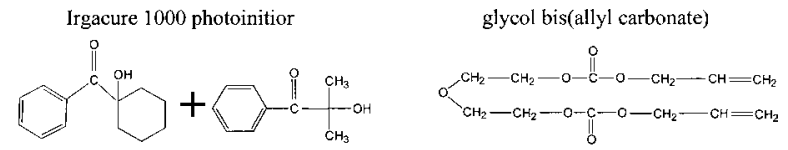

FIG. 1. Chemical composition of the photoinitiator mixture and the CR-39 monomer.

be used to differentiate the response of irradiated and unirradiated cells in bystander effect studies. This work represents a new application based on UV-radiation curing of CR-39 (30) to obtain detectors that meet the specific requirements for radiobiological studies and for bystander effect studies in particular (28). This paper describes UV polymerization of CR-39, with a controlled polymer thickness of $10 \mu \mathrm{m}$ that allows traversal by $\alpha$ particles delivered by a sealed $\alpha$-particle source. Moreover, the applicability of this material for reliable use in such radiobiology experiments was studied by validating thin CR-39 as both a petri dish and a solid-state nuclear track detector for a single detection of $\alpha$-particle tracks.

\section{MATERIALS AND METHODS}

\section{Materials}

CR-39 monomer, diethylene glycol bis(allyl carbonate), was obtained from Aldrich Chemical Company. The UV-radiation-sensitive photoinitiator used in this work was a mixture of hydroxy-iso-butyrophenone and 1-benzoyl-cyclohexanol, also known under the trade name of Irgacure 1000, obtained from Ciba Specialty Chemicals Inc. Their UV/visible spectrum shows absorption peaks at 245, 280 and $380 \mathrm{~nm}$. For this work, we used a monomer with a fixed amount of $5 \%$ photoinitiator. After the creation of free radicals in the initiation step, the propagation step consists of additions of a monomer allyl group(s). The monomer contains two allyl groups that can be polymerized. CR-39 monomer and Irgacure 1000 photoinitiators are presented in Fig. 1.

\section{Manufacturing of Mold}

To obtain thin and calibrated CR-39 films, we manufactured a $4 \times 4$ $\mathrm{cm}^{2}$ silicon tank with a high flatness rate and a micrometer-controlled depth (Fig. 2).

The mold tank was etched in a [100] cut double-sided polished silicon wafer using a $\mathrm{KOH}$ anisotropic chemical process. This choice has some major advantages for our application. First, the double-sided polished wafer ensures two parallel reference flats. Second, silicon allows many different hydrophilic, lipophilic or other interfaces to be chemically grafted using oxidation or/and other specific treatments. Third, for a perfect silicon crystal, the roughness caused by $\mathrm{KOH}$ etching remains near the polished surface of the wafer, ensuring that the polymer film remains level. Finally, anisotropic etching of a [100] silicon wafer allows us to obtain sloping edges, making it easier to remove the polymeric film from the mold after the polymerization has been performed.

After the wafer oxidation, the tank design was produced by photolithography: Four square reference pins aligned to the $\langle 110\rangle$ axes and spaced out at $4 \mathrm{~cm}$ are protected during the silica etch by using buffered $\mathrm{HF}$ (composed of 7 volumes of $40 \% \mathrm{NH} 4 \mathrm{~F}$ for 1 volume of $50 \% \mathrm{HF}$ ). The wafer was immersed in $40 \% \mathrm{KOH}$ at $55^{\circ} \mathrm{C}$ for $40 \mathrm{~min}$. The residual silica protects the reference pins. The other parts of the wafer (the tank and some draining channels) are $10.9 \pm 0.2 \mu \mathrm{m}$ deep (as measured by DEKTAK IIA “profilometer" measurements).

The top of the mold is a 4-inch stripped mask for photolithography 


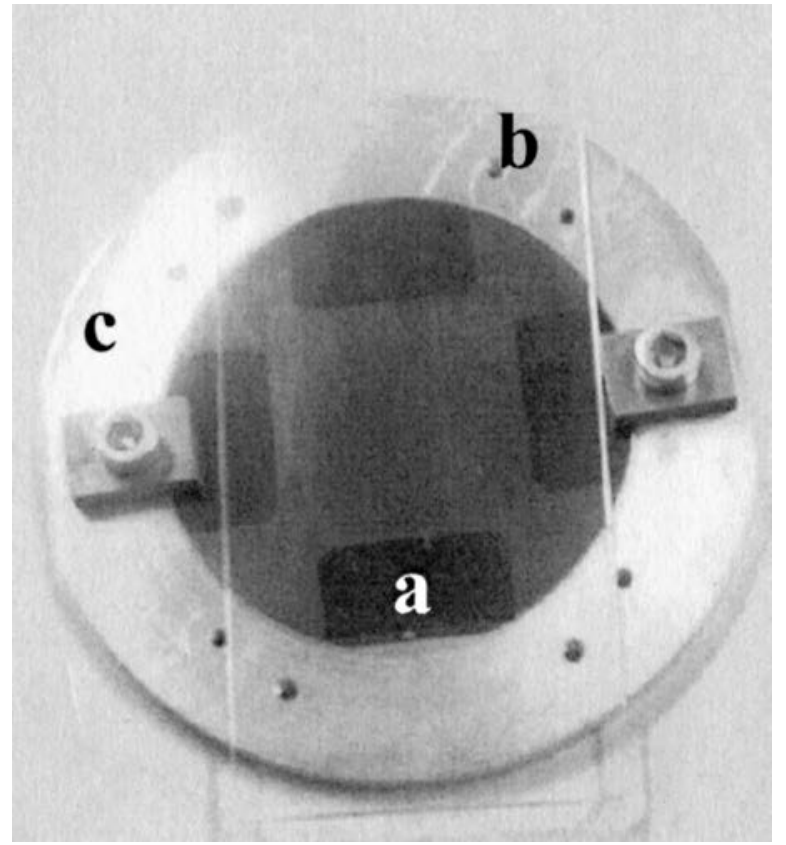

FIG. 2. Photograph of the silica tank made up of four reference pins (a), a 4-inch stripped mask for photolithography (b), and an aluminum support (c).

(BK7). It allows more than $90 \%$ near-UV transparency and a great flatness $(\lambda / 10)$, thus allowing good contact with the tank reference pins.

A third aluminum piece including screws was manufactured to hold the silicon tank; it allows a mechanical contact between the stripped mask and the four tank reference pins.

\section{Curing Procedure}

Experience shows that curing of CR-39 by UV radiation is not possible in air and requires an atmosphere of nitrogen (30). In this study, we put a 3- $\mu$ l drop of the monomer-photoinitiator mixture on the center of the silicon tank and then closed the polymerizing mold by applying a BK7 glass window on the silicon wafer aligned with the reference tank pins. The mixture spreads in the mold and becomes hermetically sandwiched between the mold and the window. This design allows CR-39 polymerization in air. The plastic foil was cured for $2 \mathrm{~h}$ in a SUNTEST CPS Heraeus cell. In this device, the samples were irradiated using a xenon arc lamp equipped with filters and reflectors for the selection of UVvisible radiation ( $300 \mathrm{~nm}<\lambda<800 \mathrm{~nm}$ ) emitted by the lamp (31). This irradiation cell was also equipped with ventilation, thus allowing polymerization of the CR-39 at an almost constant temperature of $44 \pm 2^{\circ} \mathrm{C}$ under an average light energy density of $85 \pm 5 \mathrm{~W} \mathrm{~m}^{-2}(31)$.

\section{Measurements of Polymer Thickness}

After the curing process, the polymer foil was removed from the mold and placed on a glass plate to obtain a step. Two-dimensional profile measurements were performed on the thin CR-39 foils by using a DEKTAK IIA "profilometer" which has a $Z$-axis resolution of about $5 \mathrm{~nm}$ for the smoothest surfaces. For this study, the system was used as a linear profile recorder; a 12.5 - $\mu \mathrm{m}$-radius diamond-tipped probe starts in contact with the polymer surface and is driven as far as the reference sample glass support. In this way, the thickness of the samples was determined by taking the average height between the altitudes. The homogeneity of the thickness was estimated by probing different areas of each foil.

\section{Chemical Analysis of the Polymer}

Attenuated total reflection Fourier transform infrared spectroscopy (FTIR/ATR) was employed for chemical analyses of both the solid and liquid samples. In this study, a NICOLET PC FT-IR spectrometer was used. The ATR crystal was KRS-5 with a refractive index of 2.37. The spectra were obtained using 100 scans with a resolution of $4 \mathrm{~cm}^{-1}$. The sample was positioned in contact with the totally reflecting surface of the ATR crystal, and the resulting evanescent wave was attenuated in the infrared regions of the spectrum where the sample absorbs energy.

\section{Alpha-Particle Irradiation and Spectrometry}

The response of the CR-39 samples after $\alpha$-particle irradiation was characterized prior to use for radiobiological studies. The thin CR-39 foils were irradiated with $\alpha$ particles from an ${ }^{241} \mathrm{Am}(5.48 \mathrm{MeV})$ source (AM241-EATC12 $\alpha$-particle source calibrated by CERCA framatome ANP, electrolytic deposit thickness $0.5 \mathrm{~mm}$, activity $34 \mathrm{kBq}$ ). Different thicknesses of aluminum foils were inserted between the $\alpha$-particle source and the thin CR-39 polymer to decrease the energy of the $\alpha$-particle beam. The projected range and the electronic energy loss were calculated using the SRIM 2000 computer code (32). It should be noted that the majority of the uncertainties on the experimental transmitted energy are due to the degradation of the initial beam energy by these aluminum foils; the uncertainties on the thickness of these foil can reach 15\% (as mentioned by Goodfellow). Irradiations were performed (under primary vacuum and using 21- $\mu \mathrm{m}$-thick aluminum foil on the source) at $3.5 \mathrm{MeV}$, which corresponds to the ${ }^{238} \mathrm{Pu} \alpha$-particle energy used for radiobiological experiments at the Medical Research Council (MRC). The different energy spectra of the $\alpha$ particles were obtained using a silicon barrier detector (Tennelec, type CM, active area $25 \mathrm{~mm}^{2}$ ) connected to a Tennelec multichannel analyzer (spectra were obtained over 1024 channels). Transmitted energy spectra were determined by inserting CR-39 samples in front of the silicon barrier detector.

\section{Track Etching and Morphological Analyses}

CR-39 foils were glued to the base of 2-cm-diameter glass rings to make dishes suitable for use in radiobiological studies. Prior to etching, $3 \mathrm{ml}$ of culture medium was added to improve the mechanical resistance of the detector during the etching step. The latent particle tracks were etched for the required time (between 2 and $5 \mathrm{~h}$ ) at $37^{\circ} \mathrm{C}$ by partially submerging the CR-39-based dish in $10 \mathrm{M} \mathrm{KOH}$. Therefore, only one face of the detector was etched. The etched tracks in CR-39 foils were analyzed under an optical $\mathrm{BH} 2$ Olympus microscope coupled with an RGB ColorView 8 camera and an analySIS Soft Imaging System by Olympus. This device can be used to obtain different morphological parameters of the etched tracks (diameter, area, shape factor, etc.).

\section{Irradiation of Human Fibroblast Cells}

Initial studies were carried out to show that cells could be grown successfully in CR-39-based dishes, irradiated, etched and subsequently viewed and merged with images of pits revealing the positions of $\alpha$ particle traversals with respect to the cells. HF19 human diploid fibroblasts were grown in Eagle's minimal essential medium containing $1 \mathrm{mM}$ glutamine supplemented with $10 \%$ fetal bovine serum and antibiotics at $37^{\circ} \mathrm{C}$ in $5 \% \mathrm{CO}_{2} / 95 \%$ air. A total of $2 \times 10^{5}$ cells in $2 \mathrm{ml}$ of medium were seeded into the CR-39 base of the irradiation dishes (18-mm internal diameter glass rings glued using Araldite Precision, Bostik). To aid attachment, the CR-39 dish was pretreated with Cell-Tak cell adhesive (Becton Dickinson, Bedford, MA) at a density of $3 \mu \mathrm{g} \mathrm{cm}^{-2}$ of the surface area in $0.1 M$ sodium bicarbonate buffer and was left for $30 \mathrm{~min}$ before washing three times with sterile distilled water. The cells were subsequently left for $\sim 40 \mathrm{~h}$ to grow in the dish prior to irradiation. The CR39 dishes were exposed to an essentially parallel beam of $\alpha$ particles using the MRC ${ }^{238} \mathrm{Pu} \alpha$-particle irradiator as described previously (33). The peak incident energy of the $\alpha$ particles on the CR-39 dish was 3.6 


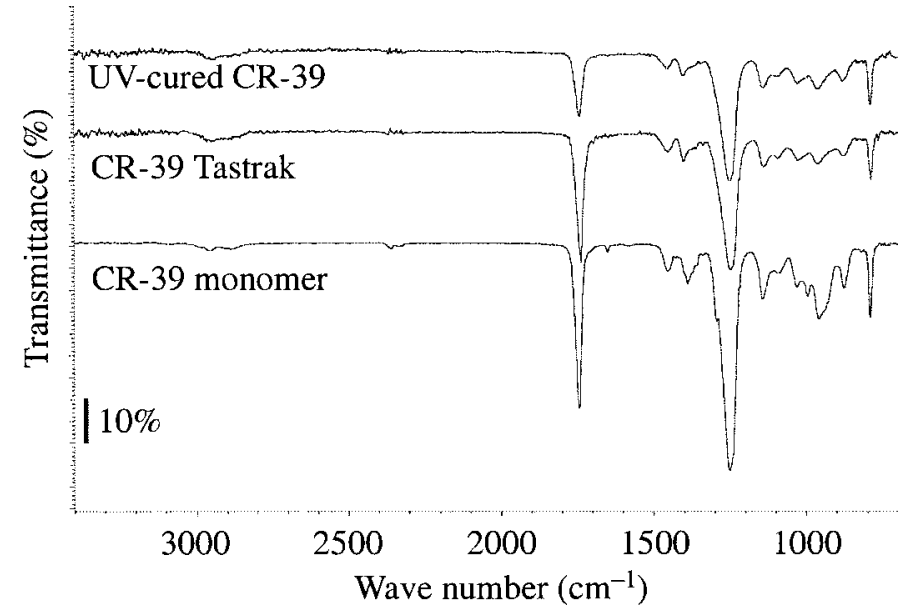

FIG. 3. FT-IR/ATR spectra of UV-radiation-cured CR-39, commercial CR-39 (Tastrak), and CR-39 monomer.

$\mathrm{MeV}$ with a $0.22 \mathrm{MeV}$ half-width at half-height. The incident $\alpha$-particle fluence was determined from previous CR-39 (Tastrak) measurements, allowing for the subsequent decay in activity with time ( $t_{1 / 2}=87.7$ years).

In these initial studies, HF19 cells grown in the CR-39-based dishes were exposed to $0.5 \mathrm{~Gy}$ of $\alpha$ particles $\left(2.6 \times 10^{6} \mathrm{~cm}^{-2}\right)$ and subsequently incubated for $8 \mathrm{~min}$. The cells were then washed with $1 \mathrm{ml}$ Eagle's minimum essential medium before fixing in $1 \mathrm{ml} 2 \%$ paraformaldehyde for $30 \mathrm{~min}$ and were subsequently washed three times with $1 \mathrm{ml}$ of PBS. The bases of the CR-39 dishes containing $2 \mathrm{ml}$ of PBS were then etched in $10 \mathrm{M} \mathrm{KOH}$ at $37^{\circ} \mathrm{C}$ for $2 \mathrm{~h}$. After removal from the dish, the CR-39 base was washed by dipping it in distilled water, and the cells were washed three more times with PBS, permeabilized using $1 \mathrm{ml}$ of methanol:acetone at $-20^{\circ} \mathrm{C}$ for $10 \mathrm{~min}$, and washed again in $3 \times 1 \mathrm{ml} \mathrm{PBS}$. Cells were blocked with $5 \%$ horse serum in PBS, washed in $4 \times 1 \mathrm{ml}$ PBS, and then covered with the anti-fading agent Vectashield mounting medium containing propidium iodide (PI) (Vector Laboratories, Burlingame, CA). The cells and etched pits were first viewed with the CR-39 base still attached to the dish. To view it with an oil immersion lens, the CR-39 base was cut out and mounted onto a cover slip with the cells in contact with the cover slip. To help keep the CR-39 flat and help the manipulation, a 15-mm-diameter brass ring was glued to the base of the dish prior to cutting out. This is necessary since oil on the CR-39 base would make the etched pits very difficult to see. The cells and CR-39 base were then viewed through the cover slip.

\section{RESULTS AND DISCUSSION}

\section{Polymer Characterization}

To compare the thin cured polymer with the commercial CR-39 (Tastrak, University of Bristol, UK), we analyzed them using attenuated total reflection Fourier transform infrared spectroscopy (FT-IR/ATR). Figure 3 shows the FTIR/ATR spectra of CR-39 monomer [diethylene glycol bis(allyl carbonate)], thin UV-radiation-cured CR-39, and 1 mm commercial CR-39 (Tastrak). These spectra present seven main peaks which are assigned to different chemical bands as shown in the Table 1.

The UV-radiation-cured polymer and Tastrak CR-39 have similar spectra. The spectrum for the monomer has higher peak intensities around 1650,1400 and 980-1000 $\mathrm{cm}^{-1}$, corresponding to allyl functions. Quantification of
TABLE 1

Characteristic Infrared Peaks of CR-39 and their Relative Chemical Functions

\begin{tabular}{cl}
\hline $\begin{array}{c}\text { Position of the } \\
\text { peaks }\left(\mathrm{cm}^{-2}\right)\end{array}$ & Chemical functions \\
\hline 1140 & $\mathrm{C}-\mathrm{O}$ ether \\
1260 & $\mathrm{C}-\mathrm{O}$ carbonate \\
$1400-1460$ & $-\mathrm{CH}_{2}-($ bending $)$ \\
1750 & $\mathrm{C}=\mathrm{O}$ carbonate $=$ \\
$2900-3000$ & $-\mathrm{CH}_{2}-($ stretching $)$ \\
\hline
\end{tabular}

both polymer and monomer allyl group signals was done after determination of the peak area ratios between the peak at $1400 \mathrm{~cm}^{-1}$ and an internal reference $\left(1260 \mathrm{~cm}^{-1}\right)$. A difference of about $60 \%$ was observed when comparing the monomer and the UV-radiation-cured polymer, confirming the polymerization process.

Polymer foils cured in the $10.9 \pm 0.2$ - $\mu$ m-deep silicon tank had a mean thickness of $10.5 \pm 0.3 \mu \mathrm{m}$ (averages \pm six different samples with four independent measurements made on each sample). These values confirm the uniformity of the polymer thickness, which is an advantage for both cell and etched-track observation under a confocal microscope. Moreover, the thinness of the polymer facilitates the traversal of low-energy $\alpha$ particles emitted from radioisotope sources but is thick enough to provide sufficient mechanical resistance.

\section{Nuclear Track Detector Properties}

The energy spectra of $\alpha$ particles incident on and transmitted through the thin CR-39 are shown in Fig. 4. These spectra are centered at $3.45 \mathrm{MeV}$ and $1.85 \mathrm{MeV}$, respectively. The measured transmitted energy is similar to the theoretical value of $1.82 \mathrm{MeV}$ calculated using the SRIM 2000 computer code (32) and corresponds to a residual range of $11.7 \mu \mathrm{m}$ in equivalent tissue medium. The calculated mean scattering angle is at about $1.2^{\circ}$, corresponding to a lateral deflection around $0.22 \mu \mathrm{m}$ after the $10-\mu \mathrm{m}$ traversal of the CR-39.

After the irradiation step, thin CR-39 foils were tested under medium weight during the etching step to validate

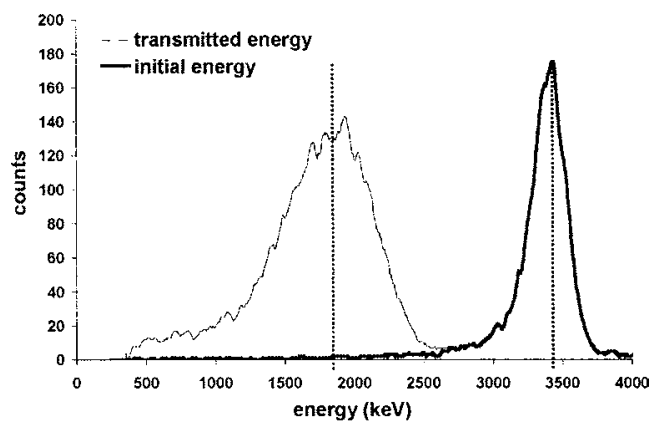

FIG. 4. Measured energy spectra of $\alpha$ particles before (initial energy) and after (transmitted energy) $10 \mu \mathrm{m}$ CR-39 traversal with $20^{\circ}$ as incident angle range. 


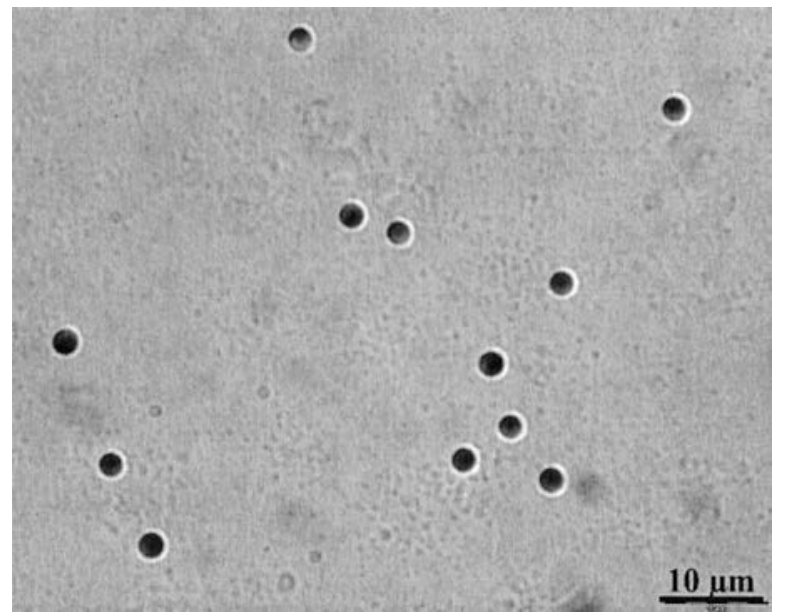

FIG. 5. Etched tracks in UV-radiation-cured CR-39 generated by 3.5 $\mathrm{MeV} \alpha$ particles. Etching conditions: $10 \mathrm{M} \mathrm{KOH}, 37^{\circ} \mathrm{C}, 4 \mathrm{~h}$.

their exploitation for radiobiological studies. The major constraint is to obtain visible etched tracks in a limited etching time to keep enough resistant residual thickness of the detector to support cell culture and prevent etched-track traversal. The bulk etch rate $\mathrm{V}_{\mathrm{B}}$ at about $1 \mu \mathrm{m} \mathrm{h}^{-1}$ was estimated at $37^{\circ} \mathrm{C}$ by measuring the loss of detector thickness as a function of etching time, $t$. Experience shows that CR-39 foils resist under medium weight during the first 5 $\mathrm{h}$ of etching time.

To have a complete characterization of the etched tracks in UV-radiation-cured CR-39, the track diameters and lengths are both of interest. Track diameters were measured directly on CR-39 surface, whereas longitudinal sections of etched pits were observed in cut edges of the colorless detector. Figure 5 shows a photograph of etched tracks in CR39 after $3.5 \mathrm{MeV}$ perpendicular $\alpha$-particle irradiation and a 4-h etching time. The molded CR-39 maintains a high-quality surface, which allows an easy track observation. Under these conditions, etched tracks are circular with a mean diameter of $2.76 \pm 0.2 \mu \mathrm{m}$. Figure 6 shows a photograph of a longitudinal section of an etched pit in CR-39 after an etching time of $4 \mathrm{~h}$. The track cross profile is well defined

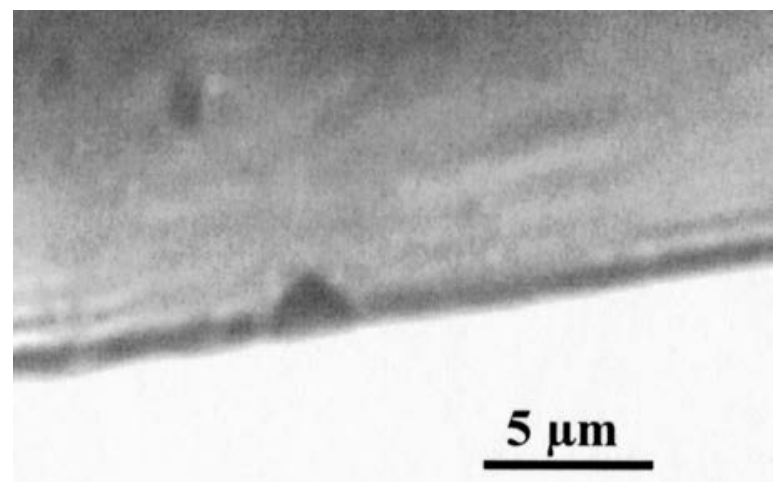

FIG. 6. Longitudinal section of an etch pit in UV-radiation-cured CR39 generated by a $3.5 \mathrm{MeV} \alpha$ particle. Etching conditions: $10 \mathrm{M} \mathrm{KOH}$, $37^{\circ} \mathrm{C}, 4 \mathrm{~h}$.

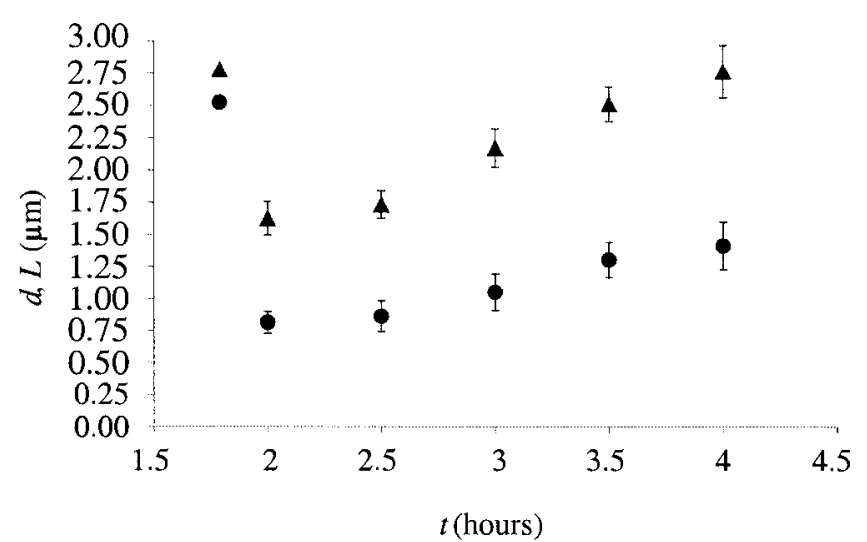

FIG. 7. Track diameter, $d$, and track length, $L$, as a function of etching time, $t$, in UV-radiation-cured CR-39 irradiated with $3.5 \mathrm{MeV} \alpha$ particles.

and has a conical shape. The etching time dependences of both track diameters and track lengths are shown in Fig. 7 with $3.5 \mathrm{MeV}$ incident energy at perpendicular incidence. This graph shows that the tracks have a diameter suitable for radiobiological studies (larger than $1.5 \mu \mathrm{m}$ ) after $2 \mathrm{~h}$ of etching time. Tracks lengths are less than $1.5 \mu \mathrm{m}$ for this etching time range. Based on the $\mathrm{V}_{\mathrm{B}}$ value and the initial detector thickness, this suggests that the cell culture and the bottom of the etched tracks are separated by at least $5 \mu \mathrm{m}$ of latent track, thus preventing contact between the etching bath and the dish inside. The measurement of both track diameters and track lengths as a function of etching time allows the mean aperture angle $\theta$ to be determined for the conical-shaped tracks according to

$$
\theta=2 \times \arctan \left(\frac{d}{2 L}\right) .
$$

Such calculations have been made for $3.5 \mathrm{MeV}$ irradiation at an incidence of $90^{\circ}$ and $10 \mathrm{M} \mathrm{KOH}$ at $37^{\circ} \mathrm{C}$ as etching conditions. The results are presented in Table 2 and show that tracks are conical-shaped and keep a constant aperture angle of about $89.7 \pm 1.5^{\circ}$ during the etching process. This suggests that, under these conditions, track etching follows a conical model (34).

The $\alpha$-particle fluence, $\Phi$, was determined as a function of irradiation time $\left(t_{i}\right)$. Statistical analyses were performed on 35 observation fields for each irradiation time. The re-

TABLE 2

Aperture Angle of Etched Tracks as a Function of Etching Time, $t$, Generated by $3.5 \mathrm{MeV} \alpha$ Particles at Perpendicular Incidence

\begin{tabular}{lc}
\hline $\mathrm{T}(\mathrm{h})$ & $\theta$ (degrees) \\
\hline 2 & 89.8 \\
2.5 & 90.2 \\
3 & 91.9 \\
3.5 & 87.9 \\
4 & 88.8 \\
\hline
\end{tabular}

Note. Etching conditions: $10 \mathrm{M} \mathrm{KOH}, 37^{\circ} \mathrm{C}, 2-4 \mathrm{~h}$. 


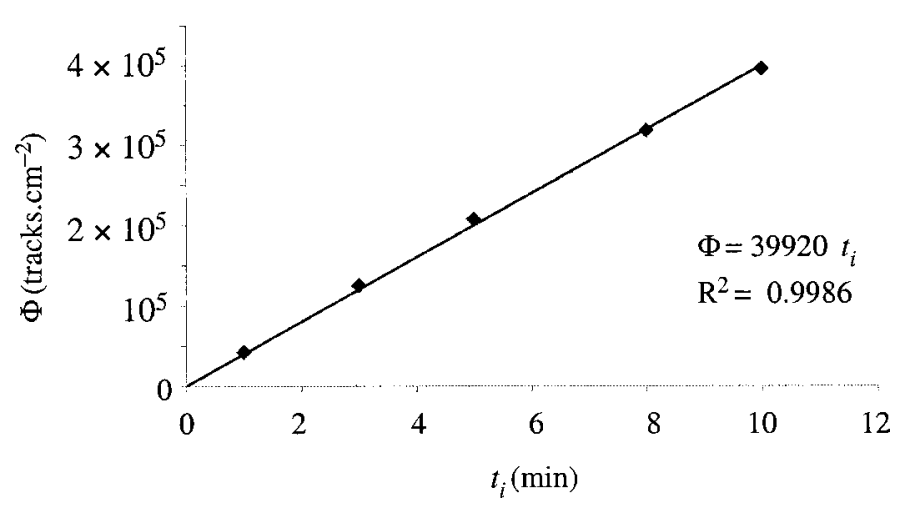

FIG. 8. Alpha-particle fluence, $\Phi$, as a function of irradiation time, $t_{i}$, in UV-radiation-cured CR-39 irradiated with $3.5 \mathrm{MeV} \alpha$ particles and etched $4 \mathrm{~h}$ in $\mathrm{KOH} 10 \mathrm{M}$ at $37^{\circ} \mathrm{C}$.

sults are presented in Fig. 8, where the dependence of track density on the irradiation time can be fitted by the linear expression

$$
\Phi=\phi \times t_{i}\left(R^{2}=0.9986\right),
$$

with the fluence rate, $\phi=39920$ tracks $\mathrm{cm}^{-2} \mathrm{~min}^{-1}$, corresponding to the mean number of incident $\alpha$ particles $\mathrm{cm}^{-2}$ per minute. This result confirms the good registration efficiency of UV-radiation-cured CR-39 which can be used under low $\alpha$-particle fluence for radiobiological experiments. Moreover, extrapolation of this linear function at $t_{i}=0$ confirms the presumed very low background of thin CR39 cured in the laboratory (see Eq. 2). To verify this last property, some detectors were partially masked during the irradiation step, etched during $4 \mathrm{~h}$ in $\mathrm{KOH}$ solution at $37^{\circ} \mathrm{C}$, and then observed under the optical microscope. Figure 9 shows a photograph of the irradiation border obtained after 5 min of irradiation. No track was observed on the masked zone of these detectors. This last result validates the use of UV-radiation-cured CR-39 for bystander experiments.

\section{Alpha-Particle Tracks through Human Fibroblast Cells}

The cells and pits marking the positions of $\alpha$-particle traversals were viewed using a confocal laser scanning microscope (Biorad-Lasersharp MRC600 on a Nikon Diaphot inverted microscope, with a Nikon Plan-Apochromat $63 \times$ N.A.1.4 oil-immersion objective lens and an ion argon laser operated at $488-\mathrm{nm}$ wavelength). Figure 10 shows the experimental configuration of the etched CR-39 layer with a stained fibroblast monolayer during observations with a confocal microscope. Confocal images of the PI-stained cell nuclei were obtained, followed by a differential interference contract (DIC) image of the pits produced in the CR-39 after etching. This was achieved using a transmission detector attached to the confocal microscope with the light from the argon laser. Images were taken of the same field of view with only the depth of focus changed. The resulting images were then merged to reveal the positions of the $\alpha$-particle traversals with respect to the cell nuclei. An example of an image obtained is shown in Fig. 11,

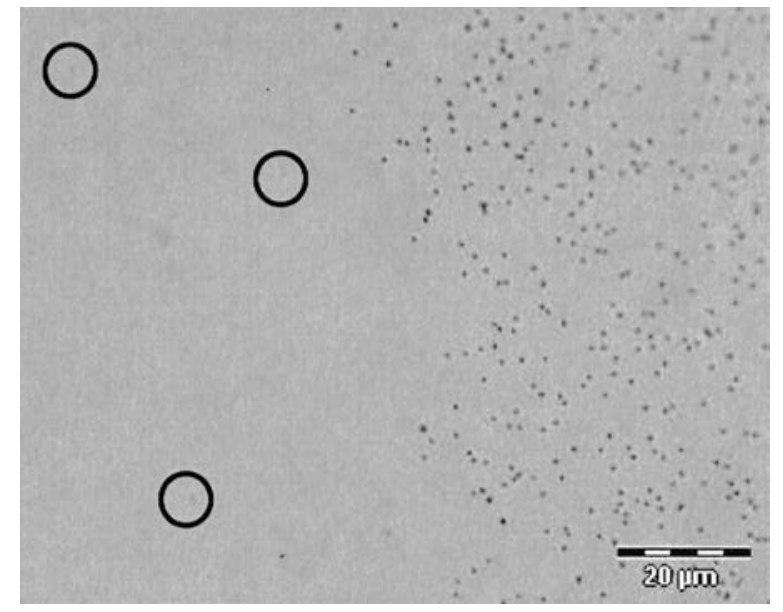

FIG. 9. Photograph of UV-radiation-cured irradiated (right) and unirradiated (left) zones CR-39 obtained after 5 min of masked exposure to $3.5 \mathrm{MeV} \alpha$ particles and $4 \mathrm{~h}$ of etching time. Note that the three faint spots in black circles are artifacts that should not be confused with $\alpha$ particle tracks.

which shows the position of $\alpha$-particle traversals relative to the cell nuclei.

The accuracy with which the $\alpha$-particle track can be positioned with respect to the cell or cell nucleus depends not only on the accuracy with which the center of the etched pit can be imaged along with any potential scatter through the CR-39 foil but also on the degree of cell movement between irradiation and the time at which the cells are fixed. Therefore, it is important for any studies using this system that the degree of cell movement is assessed. This will depend on cell type and cell density; for example, it is expected that cell movement will be greater for nonconfluent compared to confluent cells.

\section{CONCLUSION}

Unlike LR-115, the commercial thickness of CR-39 does not allow its use for direct observation and registration of

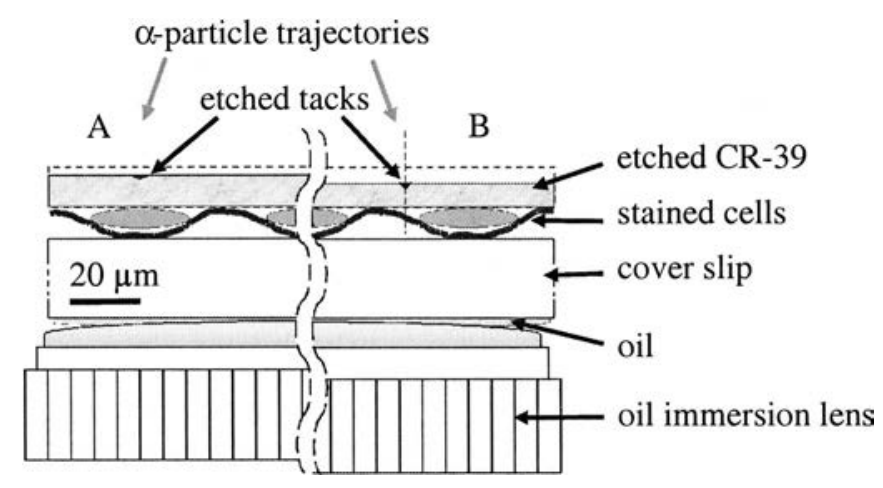

FIG. 10. Schematic of simultaneous observation of stained cells and etched tracks with a confocal microscope. This cross-section view to scale shows two configurations after $3.5 \mathrm{MeV} \alpha$-particle irradiation: part $\mathrm{A}$ (left), nuclear hit and an etching time of $2 \mathrm{~h}$; part B (right), cytoplasmic hit and an etching time of $4 \mathrm{~h}$. 


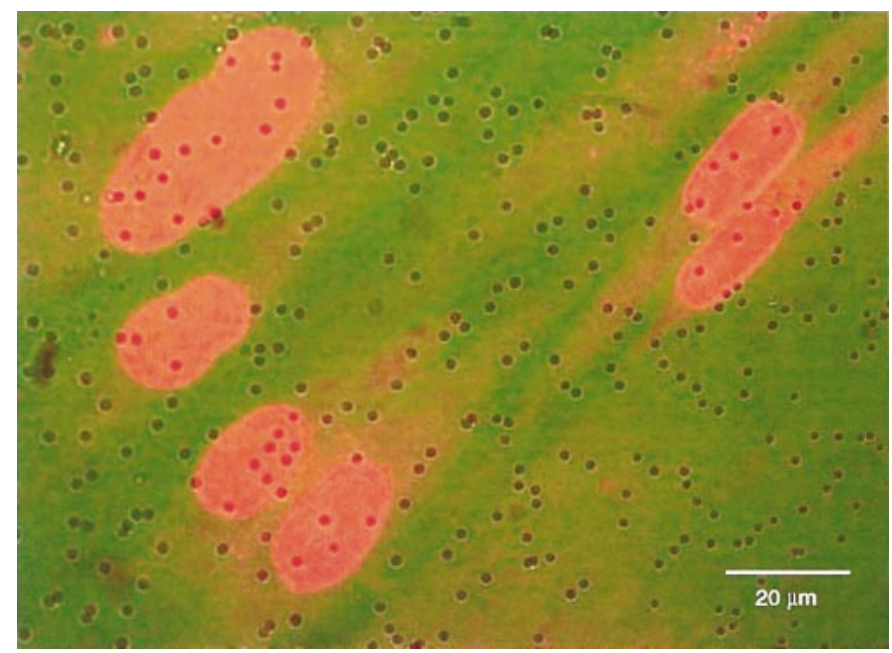

FIG. 11. HF19 human fibroblasts grown in thin CR-39-based dishes and exposed to $0.5 \mathrm{~Gy}$ of $\alpha$ particles, with the CR-39 subsequently etched for $2 \mathrm{~h}$ in $\mathrm{KOH}$ at $37^{\circ} \mathrm{C}$. Merged image showing propidium iodide-stained nuclei (red); the locations of the $\alpha$-particle traversals are shown by pits (small black circles) in the CR-39 (green).

both the number and position of $\alpha$-particle traversals through biological cells. However, CR-39 has several advantages for radiobiological experiments: biological compatibility, easy sterilization using ethanol, good ability to register light ions, essentially no false-positives, and easy characterization of etched tracks.

In this study, a detailed method using micrometric etched silica tank and UV-radiation curing of diethylene glycol bis(allyl carbonate) monomer was used to obtain $10-\mu \mathrm{m}$ thick CR-39 foils which met the requirements for radiobiological studies. FT-IR/ATR analyses confirmed the curing process which showed a similar chemical structure between UV-radiation-cured CR-39 and commercial CR-39. Despite its controlled thickness, which is thin enough for cell irradiation by isotope-produced $\alpha$ particles, the molded polymer, if carefully treated, keeps sufficient mechanical stability. The quality of the molded polymer surfaces is good with a high flatness that makes both cell and etched-track observation easier. The etching conditions used in this work allow us to obtain etched tracks in irradiated UV-cured CR39 with a usable diameter, $d$ (larger than $1.5 \mu \mathrm{m}$ ), after 2 $\mathrm{h}$ of etching time. Moreover, the measurement of track lengths after perpendicular irradiation and the bulk etch rate, $V_{B}$, allows us to identify tracks with the minimum latent track thickness (around $5 \mu \mathrm{m}$ after $4 \mathrm{~h}$ of etching time), which prevents any contact between high basic etching solution and cell culture. It was observed that etched tracks are conical-shaped with a quasi-constant aperture angle of approximately $90^{\circ}$ during the etching process. No tracks were found in the nonirradiated zones of masked detectors. This essentially zero background is due to the short time between the production and use of the polymer, which keeps this detector from being exposed to $\alpha$ particles from radon and radon daughters. Human HF19 fibroblasts cells have been grown successfully in dishes with bases made from the new CR-39 films and used for $\alpha$-particle irradiation. With subsequent etching of the CR-39 base, the positions of $\alpha$-particle traversals with respect to the cell nuclei were successfully imaged.

\section{ACKNOWLEDGMENTS}

The authors wish to thank Mr. J. P. Sabatier from the Laboratoire d'Optique P.M. Duffieux of Besançon and Mr. P. Blind from the Cetehor of Besançon for their expert technical assistance in manufacturing the aluminum support and etching silica tanks, respectively. The authors would also like to thank C. Ross, D. L. Stevens and K. M. S. Townsend at the MRC for their help with the radiobiological experiments.

\section{REFERENCES}

1. United Nations Scientific Committee on the Effects of Atomic Radiation, Sources and Effects of Ionizing Radiation. Report to the General Assembly, with scientific annexes. United Nations, New York, 1993.

2. D. T. Goodhead, Initial events in the cellular effects of ionizingradiations-clustered damage in DNA. Int. J. Radiat. Biol. 65, 7-17 (1994).

3. H. Nagasawa, J. B. Little, W. C. Inkret, S. Carpenter, K. Thompson, M. R. Raju, D. J. Chen and G. F. Strniste, Cytogenetic effects of extremely low doses of plutonium-238 alpha-particle irradiation in CHO K-1 cells. Mutat. Res. 244, 233-238 (1990).

4. H. Nagasawa and J. B. Little, Induction of sister chromatid exchanges by extremely low doses of alpha particles. Cancer Res. 52, 63946396 (1992).

5. G. E. Deshpande, S. M. Bailey, B. Marrone and B. E. Lehnert, Alphaparticle-induced sister chromatid exchange in normal human lung fibroblasts: Evidence for an extranuclear target. Radiat. Res. 145, 260-267 (1996).

6. K. M. Prise, O. V. Belyakov, M. Folkard and B. D. Michael, Studies of bystander effects in human fibroblast using a charged particle microbeam. Int. J. Radiat. Biol. 74, 793-798 (1998)

7. O. V. Belyakov, A. M. Malcolmson, M. Folkard, K. M. Prise and B. D. Michael, Direct evidence for a bystander effect of ionising radiation in primary human fibroblasts. Br. J. Cancer 84, 674-679 (2001).

8. J. R. Hickman, J. Lechner and N. Johnson, Alpha particle induced p53 protein expression in a rat lung epithelial cell strain. Cancer Res. 54, 5797-5800 (1994).

9. E. Azzam, S. M. Toledo, T. Gooding and J. B. Little, Intercellular communication is involved in the bystander regulation of gene expression in human cells exposed to very low fluences of alpha particles. Radiat. Res. 150, 497-504 (1998).

10. H. Zhou, G. Randers-Pehrson, C. A. Waldren, D. Vannais, E. J. Hall and T. K. Hei, Induction of a bystander effect of alpha particles in mammalian cells. Proc. Natl. Acad. Sci. USA 97, 2099-2104 (2000).

11. S. G. Sawant, G. Randers-Pehrson, C. R. Geard, D. J. Brenner and E. J. Hall, The bystander effect in radiation oncogenesis. I. Transformation in $\mathrm{C} 3 \mathrm{H} 10 \mathrm{~T}^{1} / 2$ cells in vitro can be initiated in unirradiated neighbors of irradiated cells. Radiat. Res. 155, 397-401 (2001).

12. S. A. Lorimore, M. A. Kadhim, D. Pocock, D. L. Papworth, D. L. Stevens, D. T. Goodhead and E. G. Wright, Chromosomal instability in descendants of unirradiated surviving cells after $\alpha$-particle irradiation. Proc. Natl. Acad. Sci. USA 95, 5730-5733 (1998).

13. M. A. Kadhim, S. J. Marsden, A. Malcolmson, M. Folkard, D. T. Goodhead, K. M. Prise and B. D. Michael, Long-term genomic instability in human lymphocytes induced by single-particle irradiation. Radiat. Res. 155, 122-126 (2001). 
14. R. Iyer and B. E. Lehnert, Effects of ionising radiation in targeted and non targeted cells. Arch. Biochem. Biophys. 376, 14-25 (2000).

15. C. Mothersill and C. Seymour, Radiation-induced bystander effects: Past history and future directions. Radiat. Res. 155, 759-767 (2001).

16. W. F. Morgan, Non-targeted and delayed effects of exposure to ionizing radiation: I. Radiation-induced genomic instability and bystander effects in vitro. Radiat. Res. 159, 567-580 (2003).

17. F. Ballarini, M. Biaggi, A. Ottolenghi and O. Sapora, Cellular communication and bystander effects: A critical review for modeling low dose radiation action. Mutat. Res. 501, 1-12 (2002).

18. C. Mothersill and C. Seymour, Medium from irradiated human epithelial cells but not human fibroblasts reduces the clonogenic survival of unirradiated cells. Int. J. Radiat. Biol. 71, 421-427 (1997).

19. H. Zhou, M. Suzuki, C. R. Geard and T. K. Hei, Effects of irradiated medium with or without cells on bystander cell responses. Mutat. Res. 499, 135-141 (2002).

20. M. A. Hill, J. R. Ford, P. Clapham, S. J. Marsden, D. L. Stevens, K. M. S. Townsend and D. T. Goodhead, Bound PCNA in nuclei of primary rat tracheal epithelial cells after exposure to very low doses of plutonium-239 particles. Radiat. Res. 163, 36-44 (2005).

21. M. Folkard, B. Vojnovic, K. M. Prise, A. G. Bowey, R. J. Locke, G. Schettino and B. D. Michael, A charged-particle microbeam. Part I. Development of an experimental system for targeting cells individually with counted particles. Int. J. Radiat. Biol. 72, 375-385 (1997).

22. M. Folkard, B. Vojnovic, K. J. Hollis, A. G. Bowey, S. J. Watts, G. Schettino, K. M. Prise and B. D. Michael, A charged-particle microbeam. Part II. A single-particle micro-collimation and detection system. Int. J. Radiat. Biol. 72, 387-395 (1997).

23. G. Randers-Pehrson, C. R. Geard, G. Johnson, C. D. Elliston and D. J. Brenner, The Columbia University single-ion microbeam. Radiat. Res. 156, 210-214 (2001).

24. M. Durante, G. F. Grossi, M. Pugliese, L. Manti, M. Nappo and G.
Gialanella, Single charged-particle damage to living cells: A new method based on track-etch detectors. Nucl. Instrum. Methods B 94 , 251-258 (1994).

25. M. Durante, G. F. Grossi, M. Pugliese and G. Gialanella, Nuclear track detectors in cellular radiation biology. Radiat. Meas. 26, 179186 (1996).

26. C. Soyland and S. P. Hassfjell, A novel ${ }^{210}$ Po-based $\alpha$-particle irradiator for radiobiological experiments with retrospective $\alpha$-particle hit per cell determination. Radiat. Environ. Biophys. 39, 125-130 (2000).

27. R. L. Fleischer, P. B. Price and R. M. Walker, Tracks of charged particles in solids. Science 149, 383-393 (1965).

28. B. Dörschel, D. Hermsdorf, S. Pieck, S. Starke, H. Thiele and F. Weickert, Studies of SSNTDs made from LR-115 in view of their applicability in radiobiological experiments with alpha particles. Nucl. Instrum. Methods B 207, 154-164 (2003).

29. B. Dörschel, D. Hermsdorf, S. Pieck, S. Starke and H. Thiele, Thickness measurements on cell monolayers using CR-39 detectors. Nucl. Instrum. Methods B 187, 525-534 (2002).

30. J. Stejny, J. Carrell and M. J. Palmer, Polymerization, structure and track recording properties of CR-39 cured with UV photoinitiators. Radiat. Meas. 32, 299-305 (2000).

31. L. Guillot, C. Dubois and A. Chambaudet, Testing of organic matrix durability in photochemical ageing using ablation measurements. Polymer Degradation Stability 72, 209-215 (2001).

32. J. Ziegler, J. Biersack and D. Marwick, SRIM-2000: The Stopping and Range of Ions in Matters. IBM Corporation, New York, 2000.

33. D. T. Goodhead, D. A. Bance, A. Stretch and R. E. Wilkinson, A versatile plutonium-238 irradiator for radiobiological studies with $\alpha$ particles. Int. J. Radiat. Biol. 59, 195-210 (1991).

34. G. Somogyi and S. A. Szalay, Track diameter kinetics in dielectric track detector. Nucl. Instrum. Methods 109, 211-232 (1973). 